\title{
A VUELTAS CON LA FINANCIACIÓN DE LOS PARTIDOS EN ESPAÑA: LA LO 8/2007 Y LAS REFORMAS DE OCTUBRE DE 2012 Y MARZO 2015
}

\author{
David Almagro Castro
}

\begin{abstract}
SUMARIO: 1. LA FINANCIACIÓN DE LOS PARTIDOS: BREVE CONTEXTUALIZACIÓN HISTÓRICA. 2. ¿POR QUÉ FINANCIAR LOS PARTIDOS? UNA APROXIMACIÓN AL ORIGEN DE LOS DIFERENTES MODELOS DE FINANCIACIÓN. 3. LA FINANCIACIÓN DE LOS PARTIDOS POLÍTICOS EN ESPAÑA: LA INDEFINICIÓN DE LA CE Y LA INCONSISTENCIA DEL LEGISLADOR ORGÁNICO. 4. LA LEY 8/2007 Y LA REFORMA DE 22 DE OCTUBRE DE 2012 (LO 5/2012): VIEJOS PROBLEMAS, SOLUCIONES PARCIALES. 5. UNA NUEVA REFORMA EN FAVOR DEL CONTROL DE LA ACTIVIDAD ECONÓMICO-FINANCIERA DE LOS PARTIDOS: LA LEY ORGÁNICA 3/2015, DE 30 DE MARZO. 6. CONCLUSIONES.
\end{abstract}

\section{LA FINANCIACIÓN DE LOS PARTIDOS: BREVE CONTEXTUALIZACIÓN HISTÓRICA}

Que los partidos ocupan lugar preferente en la estructura institucional del Estado democrático puede calificarse doctrinalmente como una afirmación obvia y repetitiva. Una relevancia sistémica que contrasta con la degradación paulatina de su percepción social como organizaciones funcionales para el sostenimiento y desarrollo del gobierno democrático. Organismos de la fiabilidad del Centro de Investigaciones Sociológicas (CIS) y la reconocida ONG Transparency International ilustran un escenario de fuerte desencanto de la ciudadanía con unos partidos percibidos como organizaciones disfuncionales e incapaces de representar y atender adecuadamente las demandas ciudada- 
nas ${ }^{1}$. De entre este elenco de demandas destaca la reforma del actual marco de financiación que posibilite avanzar hacia ese nuevo modelo de partido intensamente reclamado por la sociedad.

La razón de este desencanto se encuentra, principalmente, en la mutación funcional que han experimentado en los últimos tiempos. Concebidos originariamente como elementos vertebradores y de conexión entre la sociedad y el Estado en la materialización del principio democrático, los partidos se han transformado en una razón en sí mismo ${ }^{2}$. Su principal preocupación no parece ser la captación, articulación y satisfacción de las demandas ciudadanas, sino la expansión burocrática y la reproducción organizacional que garanticen su supervivencia ${ }^{3}$.

La centralidad sistémica de los partidos es el producto de un largo proceso histórico cuyo episodio principal aconteció en el periodo de entreguerras -con su reconocimiento legal iniciado por la doctrina y la jurisprudencia alemanas- y que tuvo su culminación, terminada la Segunda Guerra Mundial, con la definición y posterior expansión del régimen democrático como forma de gobierno de la sociedad ${ }^{4}$. La situación de interdependencia entre democracia y partidos acabó trasladándose a la propia ingeniería institucional del Estado democrático que, como es bien conocido, pasó a ser considerado un Estado de partidos 5 .

Este cambio radical de escenario jurídico encontró acomodo en el constitucionalismo racionalizado y democrático post II $^{\mathrm{a}}$ Guerra Mundial. Las Constituciones italiana (1947), alemana (1949) y francesa (1958) harían de los partidos elementos centrales del sistema democrático. La presencia de los partidos en el orden constitucional -con diferentes grados de intensidad funcional-supuso la incorporación de la financiación directa de los partidos a la agenda política europea de los años 50. El apoyo financiero del Estado se justificaba desde la doble dimensión objetiva y subjetiva de su constitucionalización. Los partidos no solo son una modalidad sui generis de ejercicio del derecho de asociación orientadas a la participación en el proceso democráti-

${ }^{1}$ La encuesta del CIS (Centro de Investigaciones Sociológicas) de Julio de 2014 sitúa a los partidos políticos como uno de los tres problemas más relevante del país (con un 26.4\%). Barómetro CIS disponible es <http://www.cis.es/cis/export/sites/default/-Archivos/Marginales/3020_3039/3033/es3033mar.pdf $>$. Transparency Internacional indica que en 2010 las instituciones más corruptas son, para la ciudadanía, los partidos políticos. Disponible en <http://www.transparency.org/country\#ESP> (acceso el 22/10/2014).

${ }^{2}$ Cf. Presno Linera, M.A., Los partidos políticos y las distorsiones jurídicas de la democracia, Ariel, Barcelona, 2000, p.11.

${ }^{3}$ Cf. FlORES D'ARCAIS, P., «La democracia tomada en serio», Claves de razón prácti$c a, \mathrm{n}^{\mathrm{o}} 2,1990$, pp. 2-14.

${ }^{4}$ Cf. KElSEN, H., Esencia y valor de la democracia, KRK ediciones, Granada, 2009.

${ }^{5}$ Cf. Garcia Pelayo, M., El Estado de Partidos, Alianza, Madrid, 1986, p. 32. 
co; también son una garantía institucional del propio sistema democrático, sin los cuales difícilmente puede llevarse a cabo la conversión de las voluntades populares en una voluntad general racionalizada y coherente ${ }^{6}$.

La década de los 60 fue escenario de múltiples cambios sociológicos con incidencia directa en la propia supervivencia económica de los partidos políticos. La irrupción de los mass media transformó radicalmente y con carácter permanente la relación de los partidos con la sociedad, obligándolos a ocupar el mayor espacio posible para poder competir política y electoralmente ${ }^{7}$. La dependencia de los partidos de la visibilidad mediática como garantía de competitividad electoral trajo aparejado un aumento exorbitante del gasto corriente. La lucha y la necesidad de organización como ethos de la política, parámetros funcionales clásicos de los partidos, se verá profundamente alterada por la incorporación de un nuevo elemento estructural: la financiación de los partidos y su necesario encaje legal ${ }^{8}$.

La irrupción de los medios de comunicación como catalizadores de la competición electoral no fue el único fenómeno social que afectó a la dinámica de funcionamiento de los partidos políticos. Nos referimos, claro está, a la conquista definitiva del sufragio universal, elevado constitucionalmente a derecho fundamental y principio elemental del Estado democrático. El caudal de nuevos electores y posibles afiliados supuso la transformación de los partidos de representación en partidos de masas, dominadores del escenario político durante dos décadas. El nuevo universo electoral, inmensamente más competitivo que el propiciado por el sufragio censitario, exige de los partidos mayor capacidad de organización y presencia en los medios propagandísticos. Los gastos organizativos en que los partidos acaban incurriendo no pueden seguir siendo atendidos mediante las contribuciones de los afiliados, hasta entonces principal eje financiero de los partidos. La profundidad de los cambios sociológicos y jurídicos ocurridos entre finales de los 40 e inicio de los 60 amenazaba con crear graves inconvenientes al funcionamiento de una maquinaria estatal que precisaba de nuevas respuestas jurídicas que permitiera contar con partidos financieramente estables ${ }^{9}$.

La conjunción de estos tres factores -la ampliación del cuerpo electoral mediante el sufragio universal, la irrupción de los mass media y la homoge-

${ }^{6}$ Cf. holgado gonzález, M., La financiación de los partidos políticos en España, Tirant lo Blanch, Valencia, 2003, p. 17

${ }^{7}$ Cf. BLANCO VALDÉs, R.L., «La problemática de la financiación de los partidos políticos en España: regulación jurídica y propuestas de reforma», Revista de Estudios Politicos (Nueva Época), no 87, 1995, p.164.

${ }^{8}$ Cf. Weber, M., Escritos políticos, Alianza, Madrid, 1991, p. 139.

9 Cf. Puhle, H.J., Crisis y cambios de los partidos catch-all, en Montero, J.R. et al., Partidos políticos: viejos conceptos y nuevos retos, Trotta, Madrid, pp.81-82. 
neización de las clases sociales- produjo una nueva transformación en el interior de los partidos de masas y su relación con el medio electoral. La identificación ideológica, hasta el momento hilo conductor de las relaciones partido -elector, dio paso a un nuevo modelo organizacional: el partido catch-all o partido de electores. Los partidos se convierten, preferentemente, en máquinas burocratizadas orientadas a la captura de votos y el triunfo electoral, dejando en un segundo plano la identificación ideológica con el electorado $^{10}$.

La fuente de financiación primaria de los partidos, privada y basada en las aportaciones dinerarias de los afiliados, se rebela insuficiente para atender las necesidades organizativas y comunicativas de los nuevos partidos catch-all. $\mathrm{Su}$ funcionamiento interno, altamente burocratizado y su función principal, la captura de votos y la victoria electoral, los aleja progresivamente de las tasas de afiliados propias de los partidos de masas. La sociedad de la información impone canales de comunicación múltiples financieramente costosos. La desideologización de los partidos ha terminado por disminuir notablemente las aportaciones de los afiliados. Este contexto de incremento de gastos operacionales y disminución de ingresos recurrentes colocó en jaque la estabilidad del propio sistema democrático, haciendo inevitable la intervención correctora del Estado.

La crisis financiera de los partidos motivó la reacción inmediata de la doctrina y el legislador en busca de respuestas jurídicas que ayudasen a reequilibrar la estabilidad del sistema. La condición de los partidos como juez y parte -ya que la legislación de turno es aprobada por los representantes del partido en el Parlamento- añadía un punto de conflictividad a las posibles soluciones jurídicas. Cualquiera que fuese el modelo de financiación elegido, para cuya definición el legislador dispone de un amplio margen de configuración, tendría una proyección inmediata sobre la naturaleza jurídica y las funciones de los partidos ${ }^{11}$.

${ }^{10}$ Cf. Blanco Valdés, R.L., Las conexiones políticas, Alianza, Madrid, 2001, p. 63.

11 Cf. Castillo, P., La financiación de partidos y candidatos en las democracias occidentales, Siglo XXI de España, Madrid, 1985; Holgado GonZÁlez, M., La financiación de los partidos politicos en España, op.cit, p. 17. La cuestión de la naturaleza jurídica de los partidos es esencial para la justificación o rechazo de la financiación pública directa por el Estado. Grosso modo, las posiciones doctrinales son tres: a) los partidos son organizaciones privadas, surgidas de la sociedad y consiguientemente independientes del Estado, que, consecuencia de la racionalización del pluralismo político a través de la contienda electoral, expresan el pluralismo político de la sociedad y, por tanto, a la ciudadanía corresponde el mantenimiento de los costes económicos derivados de tales funciones; $b$ ) Los partidos son definidos por el Estado como vehículos fundamentales para la participación política y expresión del pluralismo político. Deben, por tanto, deben recibir fondos del Estado para garantizar el adecuado cumplimiento del mandato constitucional, es decir, 


\section{2. ¿POR QUÉ FINANCIAR LOS PARTIDOS? UNA APROXIMACIÓN AL ORIGEN DE LOS DIFERENTES MODELOS DE FINANCIACIÓN}

La conversión de los partidos en elementos centrales del sistema democrático conllevó la multiplicación de sus funciones $\mathrm{y}$, correlativamente, provocó una crisis estructural y financiera sin precedentes. La trascendencia que la financiación alcanzó para la supervivencia de la propia democracia generó un debate doctrinal cuyo origen tuvo lugar en las democracias liberales anglosajonas a principios del siglo XX. En el mundo anglosajón, los partidos eran considerados asociaciones cuya vida organizativa e interna debía estar al margen de la fiscalización estatal. La creación de normas jurídicas reguladoras de la financiación de los partidos y/candidatos fue fiel reflejo de la idea de mantener este status quo de independencia. Con ello se pretendió garantizar en la medida de lo posible una doble necesidad histórica: mantener al partido al margen de cualquier presión corporativa o institucional por posibles dependencias de tipo financiero y alcanzar la igualdad de oportunidades en la contienda electoral ${ }^{12}$. Una opinión ésta no compartida por reputadas voces en la doctrina que defienden que la financiación pública de los partidos, lejos de contribuir a la igualdad de oportunidades y al pluralismo político, beneficia directamente a los partidos dominantes e impide la entrada de nuevos partidos en la competición electoral ${ }^{13}$.

La financiación partidista afectaba, igualmente y de manera tangencial, a la democracia interna en los partidos. Robert Michels anticipó indirectamente en el clásico Sociología de los partidos en la democracia moderna la incidencia que la financiación pública -a través de los salarios de los cargos públicos- llegó a tener en el refuerzo de sus estructuras oligárquicas. La situación de dependencia económica de los representantes públicos respecto a los jefes del partido incidió en la formulación de su clásica ley de hierro de la oligarquía. Para el autor, la remuneración de los servicios prestados refuerza la burocratización del partido y favorece el centralismo. La dependen-

fondos destinados a sufragar los gastos electorales exclusivamente. Los gastos ordinarios es asunto privado de los partidos en tanto que organizaciones privadas; c) Los partidos políticos no solo son asociaciones privadas elementales para la expresión del pluralismo político y la voluntad general sino también lo son en la conformación de esa voluntad general. Por tanto, deben recibir fondos tanto para los gastos electorales cuanto para los gastos ordinarios.

${ }^{12}$ Cf. Blanco VAldés, R.L. Las conexiones políticas, op.cit. pp.56-62.

${ }^{13}$ Cf. GARCía ViÑUELA, E., «Financiación pública de los partidos y cartelización de la oferta política», Revista Española de Ciencia Política n. 20, 2009, p.76; Moral Moral, $M^{a}$.C., «El control de la financiación de los partidos políticos. "Tribunal de Cuentas ante la corrupción”», Cursos de Verano de la Universidad Complutense, 1999, p. 147. 
cia económica frente a los líderes acaba por convertirse en un «círculo de hierro» que obstruye la democracia interna ${ }^{14}$.

Fue en este escenario de burocratización y militarización de los partidos donde se produjo finalmente la participación del Estado en su financiación mediante la introducción de normas jurídicas que garantizasen los dos principios antedichos: la independencia frente a las presiones corporativistas o institucionales y la igualdad de oportunidades en la contienda electoral ${ }^{15}$. La adopción de tales medidas se justifica por su incidencia directa en la calidad del debate político y en la información que el elector tiene a su disposición para la formación de sus juicios electorales ${ }^{16}$.

En un primer momento, a finales del s. XIX, Inglaterra -a través de la Corrupt and Illegal Practices Act de 1883 y posteriormente la Representation of the People Act de 1918- limitará los gastos de candidatos y/o partidos en las elecciones y buscará prohibir determinadas contribuciones a los partidos. Los EEUU incorporarán a su sistema legal las innovaciones legislativas de naturaleza negativa de los ingleses - centradas en la limitación de los gastos electorales- durante el decenio 1920-30. La Europa continental adoptó una política similar a la inglesa, si bien con diversos grados de intensidad. El predominio de la legislación de naturaleza negativa, centrada en la limitación del gasto, fue sustituido por un modelo de naturaleza positiva a mediados del s. XX. Los partidos pasaron a ser financiados directamente por el Estado, bien de forma directa -aportaciones económicas en función, preferentemente, de los resultados electorales-o bien de forma indirecta -principalmente a través de la utilización de los medios de comunicación de titularidad estatal y exenciones impositivas ${ }^{17}$.

Mientras la legislación en materia de financiación en EEUU tuvo por elemento central la regulación de los límites de gastos de la campaña electoral, derivada de la naturaleza eminentemente electoral de los partidos y la preeminencia de la figura del candidato frente a aquéllos, en Europa la legislación giró en torno a los partidos en línea con su centralidad en el Estado

${ }^{14}$ Véase Holgado González, M., La financiación de los partidos politicos en España, op.cit., p.19.

${ }^{15}$ Cf. Olaizola Nogales, I., La financiación ilegal de partidos: un foco de corrupción, Tirant lo Blanch, Valencia, 2014, p. 92.

${ }^{16}$ Cf. Dworking, R., «Uma decisão que ameaça á democracia», en Freitas, J. y TeIXeIrA, A., Direito á democracia. Ensaios transdisciplinares, Conceito Editorial, São Paulo, 2011, pp.46-47.

17 Véase Del Castillo, P., La financiación de partidos y candidatos en las democracias occidentales, Siglo XXI de España, Madrid, 1985, pp.30-63; BLANCo VALDÉS, R.L., «La problemática de la financiación de los partidos políticos en España: regulación jurídica y propuestas de reforma», op.cit., pp. 171-172. 
democrático ${ }^{18}$. La diferente naturaleza y funciones atribuidas a los partidos en uno y otro continente motivó la aparición de varios modelos alternativos de financiación. Un caso peculiar es el de Alemania, que evolucionó de un modelo de financiación limitado exclusivamente a los gastos electorales a un modelo mixto que limita la participación estatal al mantenimiento de la independencia de los partidos frente al Estado. La definición de sus elementos nucleares fue obra de la jurisprudencia del Tribunal Federal Constitucional en las sentencias de 19 de julio de 1966 y de 9 de abril de $1992^{19}$.

Los países escandinavos, por su parte, optaron por un modelo basado en la financiación exclusiva de las actividades ordinarias del partido. Cierra el cuadro de los modelos de financiación el conocido como modelo mixto, caracterizado por la financiación de la electoral y la organizativa. Este es el modelo adoptado originalmente -con diferentes grados de participación estatal- en España, Austria, Francia. Alemania lo hará tras la Sentencia del Tribunal Federal Constitucional de 9 de abril de 1992.

Las diferentes opciones de financiación partidaria pretendían poner fin a los males estructurales que han venido padeciendo los partidos. La financiación irregular, el clientelismo corporativista, la falta de transparencia financiera y la corrupción auspiciadas por la inexistencia de restricciones legislativas eficientes son fenómenos derivados, en buena medida, de la insaciable necesidad de recursos económicos que los partidos vienen precisando para la manutención de su sobredimensionada estructura organizativa ${ }^{20}$.

El partido político, realidad a la que no escapa el modelo español, es una organización que se caracteriza por tres rasgos distintivos: la elaboración de un programa homogéneo que le permita acceder al poder; la existencia de una organización cuya amplitud garantice su competitividad electoral; y, por último, una estructura permanente que lo convierta en una sigla políticamente reconocible entre los electores. Esta multiplicidad de funciones, de elevado coste financiero, hace de la captación de recursos suficientes una de las

18 Sobre el modelo estadounidense de financiación, véase SÁNCHEZ GonZÁLEZ, S., «La financiación de los partidos políticos en los Estados Unidos», Teoría y Realidad Constitucional, ${ }^{\circ}$ 6, 2000, pp.72-73.

19 Un detallado análisis sobre las consecuencias de la sentencia de 19 de julio de 1966 puede verse en GONZÁLEZ-VARAS IBAÑEZ, S., «La financiación de los partidos políticos en Alemania tras la Sentencia del Tribunal Constitucional de 9 de Abril de 1992», Revista Española de Derecho Constitucional, $\mathrm{n}^{\mathbf{0}} 36,1992$, pp. 301 y ss. Un análisis crítico del contenido de la Sentencia de 9 de abril de 1992 puede verse en SchNEIDER, H. P., «Los partidos políticos y el dinero: problemas actuales de la financiación de los partidos», $R e$ vista de las Cortes Generales, $\mathrm{n}^{\mathrm{o}} 36,1996, \mathrm{pp} .23$ y ss.

${ }^{20}$ Cf. García Viñuela, E. y GonzÁlez de Aguiar, C., «Regulación al servicio de los reguladores. La ley de financiación de los partidos políticos de 2007», XIII Encuentro de economía pública, 2011, p. 6. 
preocupaciones principales de los partidos. La suma de las necesidades financieras ordinarias, junto a las derivadas de las modernas campañas electorales, nos permite vislumbrar la importancia que la financiación tiene para la correcta comprensión del modelo actual de partido ${ }^{21}$.

\section{LA FINANCIACIÓN DE LOS PARTIDOS POLÍTICOS EN ESPAÑA: LA INDEFINICIÓN DE LA CE Y LA INCONSISTENCIA DEL LEGISLADOR ORGÁNICO}

La CE, como es bien sabido, no establece un modelo concreto de financiación de los partidos políticos. El art. 6, al definir sus notas esenciales, no alude a la cuestión de la financiación. Un silencio que se reproduce a lo largo de todo el texto constitucional. La falta de referencia expresa no supone una invitación a que los partidos disfruten de total autonomía a la hora de decidirse por uno u otro modelo financiero. El mandato constitucional de ejercer su actividad «de acuerdo a la Constitución y la ley» legitima a los poderes públicos, y principalmente al legislador, a imponerle un conjunto de medidas de control y transparencia financieras.

La financiación partidaria es materia de indudable repercusión para el correcto funcionamiento de los principios fundamentales en que se sustancia el Estado democrático. El marco constitucional general -de referencia obligada para el legislador orgánico- está compuesto por el siguiente cuadro constitucional: a) La definición en el artículo 1CE del Estado español como democrático y la condición de la libertad, igualdad y pluralismo político como valores superiores del ordenamiento jurídico; b) La centralidad de los partidos en el correcto funcionamiento del sistema democrático, definida en el art. 6CE; c) La libertad de actuación de los partidos del propio artículo 6; d) El principio general de participación política del artículo 9.2 CE; e) El principio de legalidad e interdicción de la arbitrariedad de los poderes públicos del artículo 9.3 CE; f) La libertad ideológica y de expresión de los artículos 16 y $20 \mathrm{CE}$; g) El derecho de participación política del art. $23 \mathrm{CE}^{22}$.

Este grupo de principios y derechos constitucionales son de obligado cumplimiento para el legislador a la hora de regular la financiación de los partidos. La libertad y el pluralismo político del artículo 1, las funciones de los partidos del artículo 6 y la igualdad de acceso a los cargos representativos del artículo 23.2CE justifican la financiación estatal. El objetivo general es la promoción de la equidad en la competición electoral. Por otra parte, la liber-

${ }^{21}$ Cf. Pérez Royo, J., Curso de Derecho Constitucional, 12 ed., Marcial Pons, Madrid, 2011, p. 531.

${ }^{22}$ Cf. SÁnchez MuÑoz, O., «La financiación de los partidos políticos en España: ideas para un debate», Revista Española de Derecho Constitucional, nº 99, 2013, p.164. 
tad de actuación de los partidos y las libertades de expresión e ideológica de los individuos de los artículos 6,16 y $20 \mathrm{CE}$ respectivamente posibilitan la inclusión de elementos propios de la financiación privada. Por último, el artículo 9.3 CE justifica la imposición de controles que fomenten la transparencia y el cumplimiento de la legalidad vigente fortaleciendo la independencia de los poderes democráticos sobre el poder económico ${ }^{23}$.

La financiación partidista encuentra su origen legal en la aprobación del Real Decreto-Ley 20/1977 de 18 de marzo, sobre Normas electorales y la Ley 54/1978 de 4 de diciembre, de Partidos Políticos ${ }^{24}$. Completan el cuerpo normativo la Ley Orgánica 5/1985, de 19 de junio, del Régimen Electoral General (LOREG, Título II, Capítulo VI); la Ley Orgánica 3/1987, de 2 de julio, sobre Financiación de los Partidos Políticos (LOFPP). Este primer bloque normativo, vigente por espacio de treinta años, estableció en su origen un modelo de financiación preferentemente público. La justificación inicial era la inevitabilidad de la financiación estatal en la consolidación del sistema de partidos y la incipiente democracia española. Debe decirse que el modelo adoptado tuvo el efecto positivo de reforzar y profesionalizar unas estructuras partidistas extremamente débiles. La LO 3/87 introdujo elementos propios de un modelo mixto, si bien la desproporción entre los recursos procedentes de la esfera pública y la privada lo convertían en un modelo prácticamente público. Esta tendencia hacia la publificación del modelo de financiación de los partidos alcanzó su cénit con la actual Ley Orgánica 8/2007, de 4 de julio, sobre Financiación de los Partidos políticos sustitutiva de la anterior (en adelante LO 8/2007) ${ }^{25}$.

El legislador orgánico ha ido perfilando un modelo aparentemente mixto de financiación que de acuerdo con parte de la doctrina busca la consecución de tres resultados prácticos elementales: la suficiencia y estabilidad de los recursos del partido que maximice su independencia frente a los lobbies; la igualdad de oportunidades que permita a los partidos competir equitativamente en la contienda electoral; posibilitar una interconexión suficiente entre partidos y sociedad civil, de forma a evitar su conversión en organizaciones

${ }^{23}$ Cf. Gil Castellano, J., «La financiación de los partidos políticos: el estado de la cuestión», Cuadernos Constitucionales de la Cátedra Fadrique Furió Ceriol, no 36/37, 2001, p. 254; RUIZ-RICO RUIZ, G., «La lucha contra la corrupción desde el Estado constitucional de derecho: la legislación sobre financiación de partidos políticos en España», Cuadernos Manuel Giménez Abad, nº 7, 2014, p. 230.

${ }^{24}$ Véase García Viñuela, E. y Artés CASElles, J., «El gasto público en financiación política: las subvenciones para el funcionamiento ordinario de los partidos», Revista de Estudios Políticos (Nueva Época), nº 128, 2005, p. 258.

${ }^{25}$ Cf. Santano, A.C., «La financiación ordinaria de los partidos políticos en España - nuevas normas, viejos desafíos», Revista General de Derecho Constitucional, n 19 , 2014, p. 2. 
parasitarias despreocupadas con su función de captación y renovación de la masa de afiliados. La transparencia en la gestión y el control de los actos partidarios completan el cuadro general de objetivos ${ }^{26}$.

Si hacemos caso a los objetivos generales buscados por este sistema y descontamos el incipiente modelo de los años 77 y 78 -orientado a la consolidación del sistema de partidos y la democracia- lo cierto es que las posteriores reformas y avances arrojan un resultado irregular y ciertamente decepcionante. El modelo original, fruto principalmente de la improvisación, y de longevidad bien superior a la esperada inicialmente acabó no solo por responder a las demandas iniciales de las fuerzas políticas protagonistas de la Transición; también terminó, en una inversión de sus objetivos originales, por dilatarse en el tiempo al satisfacer las prioridades de los interesados y de aquellos que obtuvieron un éxito electoral inmediato. Los beneficiarios acabaron postergando los cambios normativos que pusieran término a la improvisación y las insuficiencias del modelo de financiación de los partidos ${ }^{27}$.

En este punto, como en otros tantos relativos al Derecho de Partidos, el legislador viene mostrando una tendencia marcadamente conservadora en el mantenimiento de las prerrogativas partidarias. La consolidación del gobierno democrático no ha servido para poner freno al constante incremento del gasto estata ${ }^{28}$. Los partidos continúan inmersos en una espiral de incremento de gastos que dan lugar a la creación de nuevas necesidades financieras. El resultado de esta dinámica de actuación es una cierta hipertrofia organizativa y patrimonial si atendemos al volumen de personas que trabajan en los partidos y al patrimonio inmobiliario de que disponen. La única excepción a esta tendencia de captación creciente de recursos estatales fue el recorte del 20\% introducido en la reforma de la LO 8/2007. Una actitud forzada, qué duda cabe, por la severa crisis económica iniciada en 2008 que aun planea por nuestro país ${ }^{29}$.

Las vías de financiación establecidas en al artículo 2 de la LO 8/2007bajo el título Recursos económicos- permite a los partidos captar fondos públicos y privados con los que atender a las diversas funciones burocráticas,

${ }^{26}$ Cf. García Viñuela, E. y González de Aguilar, C., «Financiación pública de los partidos y cartelización de la oferta política», op. cit, p.146; SÁNCHEZ MUÑOZ, O., «La financiación de los partidos políticos en España: ideas para un debate», op. cit, p. 167; Olaizola Nogales, I., «La financiación ilegal de partidos: un foco de corrupción», op. cit, pp. 92 y ss.

${ }_{27}$ Cf. SAnTANO, A.C., «La financiación ordinaria de los partidos políticos en España - nuevas normas, viejos desafíos», op. cit., p. 4.

${ }^{28}$ Cf. Ariño OrTiZ, G., La financiación de los partidos políticos. Madrid: Foro de la Sociedad civil, 2009, p. 15.

${ }^{29}$ Cf. SÁnchez MuÑoz, O., «La financiación de los partidos políticos en España: ideas para un debate», op. cit., p. 68. 
organizativas, electorales e institucionales. La principal partida en materia de financiación es la que atiende al nombre de gastos de carácter ordinario anual. Su configuración pretende, con las limitaciones que se pondrán de manifiesto posteriormente, entroncar con el objetivo principal de los sistemas mixtos de garantizar la independencia del partido frente a otros sujetos, grupos o centros de poder en el ejercicio de sus actividades permanentes y contribuir a la igualdad de oportunidades de aquellas organizaciones partidarias con una mínima expresividad social.

La fórmula adoptada para su cálculo es el cómputo de los escaños y votos obtenidos en las últimas elecciones al Congreso establecida en el artículo 3.2. La cantidad a percibir por cada formación depende de las variables proporción del número de escaños y votos obtenidos y de un criterio de división en terceras partes, correspondiendo un tercio en función de los escaños y los otros dos en función del número de votos. Este método contable, no cabe duda, beneficia a los partidos con mayor representación parlamentaria, beneficiados doblemente por la baja proporcionalidad de la fórmula $\mathrm{D}^{\prime} \mathrm{Hont}$ de asignación de escaños.

La LO 8/2007 ha introducido en su artículo $3^{\circ}$ un factor de corrección largamente demandado por algunas fuerzas políticas minoritarias en la distribución de las ayudas estatales para los gastos ordinarios. La legislación de 1987 establecía que dos tercios de los fondos públicos se distribuyesen entre aquellos partidos que superasen la barrera electoral del 3\% en la asignación de escaños. Por el contrario, el artículo 3.2 de la LO 8/2007 contabiliza todos los votos obtenidos a nivel nacional y no exclusivamente en la metodología de 1987. Este cálculo pretende impulsar la igualdad de oportunidades, beneficiando a aquellas formaciones políticas con una distribución del voto difusa y con dificultades para superar la barrera electoral. Puede considerarse, dicho en términos coloquiales, una concesión de los grandes partidos a los minoritarios.

No puede decirse lo mismo respecto del segundo bloque de subvenciones, el destinado a cubrir los gastos electorales ocasionados con motivo de los diferentes procesos electivos. Un capítulo de gastos que no ha merecido otra respuesta del legislador que la mera remisión al artículo 175 de la LOREG. Es bien conocido que este dispositivo únicamente retribuye aquellos votos obtenidos en las circunscripciones en las que se haya logrado escaño, quedando descontados aquellos votos no traducidos en escaños. El legislador ha optado por seguir obviando las dificultades que la escasa magnitud de la gran mayoría de las circunscripciones electorales ocasiona a los partidos minoritarios nacionales con fuerte dispersión del voto en todo el territorio nacional.

Este modelo contable, que excluye del cobro de subvenciones a las agrupaciones extraparlamentarias y a aquellas que aun obteniendo votos en diferentes circunscripciones no alcanzan el escaño parlamentario, persiste en 
fomentar un modelo reduccionista y desproporcionadamente orientado a la función de «representación parlamentaria» de los partidos. Dicho en otros términos: el legislador no considera dignas de atención estatal otras funciones relevantes desempeñadas por los partidos fuera del espectro parlamentario. Sería deseable la reforma de esta disposición legal con el objetivo de eliminar estas desigualdades carentes de justificación ${ }^{30}$.

La posición dominante de los partidos mayoritarios no se ciñe a los comicios electorales regulares. El apartado d) del artículo 2.1 de la LO 8/2007, en una decisión cuanto menos sorpresiva, otorga subvenciones extraordinarias para la realización de campañas de propaganda en el caso de celebración de referéndum y de acuerdo a las condiciones establecidas en la LOMR. El artículo 14 de este cuerpo legal dispone que el uso de espacios gratuitos en los medios de difusión públicos quede reservado a aquellos partidos con representación parlamentaria en las Cortes Generales.

El cuarto grupo de subvenciones objeto de análisis se dirige a los grupos parlamentarios y grupos pertenecientes a la esfera local y tiene el propósito de financiar las actividades propias del partido en las Cámaras y corporaciones (artículo 2.1 e)). La generalidad de esta regulación debería ser completada a efectos de garantizar su suficiencia y estabilidad, evitando el que se conviertan en instrumentos de presión en manos de las mayorías.

Cierra el cuadro de subvenciones las otorgadas a asociaciones y fundaciones vinculadas orgánicamente a los partidos. Estas entidades se han convertido, desde la aprobación de la LO 8/2007, en la puerta trasera de entrada de recursos públicos y privados a los partidos vía asociaciones y fundaciones a ellos vinculadas. La Disposición Adicional Séptima de dicha ley introdujo dos gateras por las cuales los partidos pueden eludir las restricciones impuestas por la ley. La primera, la ampliación a $120.000 €$ del límite de donaciones realizadas por persona física o jurídica tratándose de fundaciones y asociaciones. Esta medida suele ser vía de entrada irregular de capitales ante la vinculación financiera y económica que partidos, asociaciones y fundaciones suelen tener.

Los informes del Tribunal de Cuentas posteriores a la entrada en vigor de la LO 8/2007 ponen de manifiesto la existencia de firmas de convenios de colaboración entre fundaciones y empresas privadas, rodeados de tal vaguedad en sus cláusulas y contraprestaciones que el órgano fiscalizador las ha terminado considerando como donaciones que en no pocos casos han excedido el límite de los $120.000 €$. En otros casos, se ha utilizado el ardid de dividir

${ }^{30}$ Véase Presno Linera, M.A., «La reforma del sistema de financiación de los partidos políticos», Revista Española de Derecho Constitucional, no 19, 1999, p. 218; SÁNCHEZ MuÑoz, O., «La financiación de los partidos políticos en España: ideas para un debate», op. cit., p. 175 . 
las cantidades para no sobrepasar tal límite. En segundo lugar, la propia $\mathrm{DA} 7^{\mathrm{a}}$ establece que las fundaciones no están sometidas a la restricción de recibir donaciones de empresas privadas con contrato vigente con las Administraciones, organismos o empresas públicas ${ }^{31}$.

La Disposición Transitoria Segunda de la Ley era otra puerta giratoria a la entrada de financiación irregular. Los partidos eran libres para llegar a acuerdos con entidades financieras sobre las condiciones de renegociación y/o condonación de eventuales deudas que pudieran tener. Esta disposición suponía una vía de financiación irregular repetidamente criticada por el Tribunal de Cuentas en sus Informes de Fiscalización. Felizmente, la reforma de la LO 8/2007 ha derogado tal Disposición Transitoria Segunda e imposibilitado esta recurrente vía de financiación irregular ${ }^{32}$.

El balance del marco público de subvenciones establecido en la LO 8/2007 es manifiestamente mejorable a la luz de estos argumentos. La regulación legal prevé un modelo de subvenciones excesivamente complaciente y generoso con las formaciones mayoritarias nacionales -PSOE y PP- y los partidos nacionalistas - CIU y PNV- frente a los partidos de electorado más disperso como IU. La igualdad de trato, principio básico del sistema de financiación, se ve contrariada por la disparidad de criterios dispensados a los partidos parlamentarios y extraparlamentarios y el descarado privilegio de los partidos mayoritarios frente a los minoritarios. El resultado es un refuerzo del status quo que dificulta en extremo la entrada en el escenario político de partidos de carácter nacional con voto disperso y continúa favoreciendo a los partidos nacionalistas con voto concentrado ${ }^{33}$.

El TC ligó la financiación pública de los partidos al desempeño de una función en el proceso electoral ${ }^{34}$. Parece sensato que tan solo aquellas organizaciones que realicen dicha tarea con un mínimo de seriedad y rigor puedan acceder a las arcas estatales. La desproporción se produce cuando se condiciona la recepción de la subvenciones al éxito electoral, es decir, a la obtención de la representación parlamentaria en un sistema que, como el español, no favorece precisamente la proporcionalidad por las consabidas deficiencias de ingeniera electoral.

${ }^{31}$ Cf. Rodríguez LóPEz, A., «La financiación de la actividad ordinaria de los partidos políticos en la legislación española», Actualidad administrativa, n. 13, 2010, p. 1569; SÁNCHEZ MuÑOZ, O., «La financiación de los partidos políticos en España: ideas para un debate», op. cit., p. 163.

32 Vid. art. 13 LO 5/2012.

${ }^{33}$ Cf. Martínez Cuevas, Ma . D. Régimen jurídico de los partidos políticos, Marcial Pons, Madrid, 2006, p. 137; PreSno LinerA, M.A., Los partidos politicos y las distorsiones jurídicas de la democracia, op.cit., pp. 208 y ss.

34 Vid. STC 3/1981. 
La constitucionalidad de esta restricción, legítima en sus fines al impedir la proliferación de partidos que por su escasa base electoral no desempeñen la función de instrumento fundamental para la participación política del artículo $6 \mathrm{CE}$, se ve en entredicho ante el medio legislativo establecido al excluir igualmente a aquellos que a pesar de no tener representantes electos cuentan con un caudal de votos mínimamente expresivo que contribuye a enriquecer el debate político ${ }^{35}$.

La cuantía final que los partidos vienen recibiendo del Estado para la sostenibilidad de su funcionamiento ordinario ha de considerarse desorbitada si nos atenemos a su presunta naturaleza mixta. La cifra se sitúa en un mínimo del $75 \%$ de los ingresos de los partidos, cuantía variable según cada partido y si se trata o no de año electoral. Esta generosidad estatal-favorecida por la homogeneidad entre los hacedores de la ley y los beneficiarios de la misma- ha acabado por hacer de los partidos organizaciones desmedidamente dependientes de los presupuestos públicos. Por otra parte, la LO 8/2007 viene mostrándose claramente insuficiente en la promoción de las funciones sociales de los partidos y la reducción de la estatalización de las fuentes de ingresos de los partidos.

La regulación actual fracasa en la promoción de las microdonaciones procedentes de personas físicas. La cuantía de $100.000 €$ es desproporcionada y las deducciones fiscales en el caso de mecenazgo es especialmente sugerente para las sociedades mercantiles, ya que al tributar por el Impuesto de Sociedad puede llegar al 35\% de la base de la deducción, frente a un 25\% en el caso de personas físicas. Por último, la ley propone algunas medidas interesantes dirigidas a corregir el déficit de afiliación que los partidos vienen experimentando en España. Las cuotas de afiliación, así como las restantes aportaciones realizadas a los partidos por personas físicas, resultan deducibles de la base del IRPF. La cifra de $600 €$ máximo parece excesivamente baja ${ }^{36}$.

Resumiendo, la excesiva complacencia financiera ha desestimulado la función de intermediación social, movilización de la opinión pública y legitimación del conjunto del sistema político que los partidos deben ejercer. El manantial de financiación pública del que disfrutan ha terminado por acomodarlos y volverlos despreocupados con la recaudación de fondos en los sectores sociales afines a su ideología, sea a través de donaciones, sea a través de las cuotas de nuevos afiliados ${ }^{37}$. En este sentido, debe decirse que parte im-

${ }^{35}$ Cf. SÁNCHEZ MuÑoz, O., «La financiación de los partidos políticos en España: ideas para un debate», op. cit., p. 176.

36 Cf. SÁNCHEZ MuÑOZ, O., «La financiación de los partidos políticos en España: ideas para un debate», op. cit., p. 181; SANTANO, A.C., «La financiación ordinaria de los partidos políticos en España - nuevas normas, viejos desafíos», op. cit., p. 13.

${ }^{37}$ Cf. Olaizola Nogales, I., La financiación ilegal de partidos: un foco de corrupción, op.cit, p. 94. 
portante del dinero recaudado por los partidos mediante el concepto «cuotas» procede del salario obtenido por aquellos afiliados que desempeñan algún tipo de cargo público.

El actual sistema de financiación pública tampoco se ha revelado un instrumento eficaz en la lucha contra la financiación irregular que, como suele afirmarse, puede verse incentivada por la insuficiencia de la financiación pública y la correlativa dependencia del dinero privado. Los escándalos vinculados a la financiación irregular han sido una constante en la vida de los partidos $^{38}$. Los grandilocuentes anuncios de los máximos responsables institucionales en los últimos meses se han traducido en la incorporación de la financiación irregular como delito al Código Penal en unas condiciones tachadas de decepcionantes y muy posiblemente ineficientes. La fijación de la cantidad de 500.000€ como límite para la consideración de la financiación irregular como delito resulta a todas luces desproporcionada. El legislador no ha tenido en cuenta los precedentes más recientes -el conocido como caso Bárcenas es bien ilustrativo- a la hora de fijar un límite económico realista para la consideración de esta figura como delito. Llegados a este punto, y aunque no sea el objeto de este artículo, sería deseable que el propio legislador tomase una actitud más decisiva en el endurecimiento de las penas previstas para otros delitos asociados a la corrupción política como la prevaricación, el cohecho, el tráfico de influencias y el fraude y exacciones ilegales.

El otro bloque de financiación, el compuesto por los recursos privados, se regula en el artículo 2.2 de la $\mathrm{LO} 8 / 2007$. La primera fuente de financiación privada legalmente establecida son las contribuciones de los afiliados del artículo $4^{\circ} .1$. La fijación de su importe es prerrogativa interna de los partidos, de acuerdo a la libertad de actuación y organización interna de que disponen. Su relevancia teórica contrasta con su importancia real en el sostenimiento de los gastos corrientes de los partidos, calificable de marginal. Las razones de su irrelevancia son, principalmente, dos: a) El ostracismo a que los partidos fueron condenados durante la dictadura franquista, caldo de cultivo de una cultura de desmovilización política mantenida hasta nuestros días; b) La actitud pasiva de los partidos en su función de imbricación con la sociedad

${ }^{38}$ La financiación irregular ha sido una constante en los partidos políticos desde los inicios de la democracia, viéndose amparada por una legislación continuamente ineficiente y principalmente dirigida a garantizar la supervivencia financiera de los partidos a costa del erario público. Ejemplos prácticos no faltan. A los consabidos casos de financiación irregular del PSOE de los años 80 (Caso Filesa), los varios casos de CIU (el popularmente conocido como el 3\%, el Caso Palau de La Música y más recientemente el Caso Oriol Puyol, la Operación Pretoria) se suma recientemente el PP (Casos Gürtel y Bárcenas, ambos en instrucción judicial). Una práctica, en definitiva, persistentemente presente desde la reinstauración de la democracia española. 
fuera de los periodos electorales, dinámica que refuerza las eximias tasas de afiliación de los partidos españoles, una de las más bajas en Europa. El resultado fue el paso directo de los partidos españoles al modelo catch all sin que lograran conservar mínimamente los rasgos propios de los partidos de masas -la fuerte ideologización y un número significativo de afiliados comprometidos con la suficiencia financiera del partido-, a lo que se añadiría los rasgos heredados de la etapa franquista de la desmovilización y la baja afiliación ${ }^{39}$.

El segundo bloque de la financiación privada es el resultado de las actividades propias del partido y sus rendimientos patrimoniales. El apartado c) del artículo $2^{\circ}$ alude a las donaciones realizadas por terceras personas. La limitación de las donaciones y la prohibición de las anónimas, permitidas por la legislación anterior, es un acierto del legislador en materia de transparencia. Esta medida debería complementarse con la exigencia de publicar los datos de identificación de los donantes. Sin embargo, ni el artículo 14.5 -que limita la identificación de los donantes a efectos de fiscalización por el TC-, ni el 19.2, que impone el más estricto sigilo de los datos, informes o antecedentes que afecten a la intimidad de las personas.

El principal punto de conflicto es la insuficiente regulación de los préstamos bancarios del artículo 4.4. La LO 8/2007 no establece limitación alguna al endeudamiento de los partidos. No es ésta la única interrogante. Igualmente, sorprende la vaguedad de las condiciones establecidas para la renegociación de deudas. Como contrapeso, el art. 15.5, párrafo $2^{\circ}$ establece la obligación de que los partidos anexen a la memoria que han de presentar ante el Tribunal de Cuentas (en adelante, TC) un informe detallado sobre las condiciones contractuales de los créditos y préstamos. La Disposición Transitoria $2^{\mathrm{a}}$ les impone el deber de informar al TC y al Banco de España de los acuerdos de renegociación de deudas. Estas medidas, calificables de acertadas, son insuficientes a efectos de la transparencia debida.

La histórica permisividad de la legislación española ha sido y es causa primaria de la situación de sobreexposición de los partidos a la influencia de las entidades bancarias y su consecuente sobreendeudamiento. Ejemplos, lamentablemente, sobran en los últimos años. La vaguedad de las cláusulas de renegociación de deudas entre los partidos y las entidades crediticias ha estimulado la condonación parcial o total de las deudas, dando entrada a una puerta falsa a través de la cual burlar el límite legal de las aportaciones privadas. La Disposición Adicional Segunda ha resuelto este problema en unos términos excesivamente generales, al afirmar que tales acuerdos «serán los admitidos según los usos y costumbres del tráfico mercantil habitual entre las partes y no les serán de aplicación los requisitos y limitaciones» que la propia

${ }^{39}$ Cf. SANTANO, A.C., «La financiación ordinaria de los partidos políticos en España - nuevas normas, viejos desafíos», op. cit., pp. 3-4. 
Ley regula para las aportaciones privadas. La desregulación operada por la LO 8/2007, dando manga ancha a los acuerdos de renegociación, no se ha rebelado una medida eficiente ni en la reducción de la dependencia de los partidos respecto de las entidades financieras ni en su elevado grado de endeudamiento ${ }^{40}$.

Las fuentes primordiales de financiación privada continúan siendo los créditos o préstamos concedidos por las entidades crediticias. La actual regulación legal se sitúa a medio camino de los dos modelos alternativos de financiación privada -la financiación ciudadana o el modelo liberal-. Optar por la primera vía implicaría, además de acabar con las donaciones jurídicas, incentivar ex lege las aportaciones ciudadanas de reducida cuantía. Decantarse por el modelo liberal puro exigiría mejorar la transparencia de las aportaciones privadas. El modelo español no se decanta por ninguna de estas soluciones. Permite, sin dejar de desconfiar, las donaciones privadas; concede un protagonismo desmedido a las entidades bancarias en la financiación privada; regula vagamente las relaciones entre ambos en materia de créditos y renegociación de deudas; por último, es manifiestamente mejorable en el control de su aplicación ${ }^{41}$.

La evidente desproporción entre las dos fuentes de financiación establecidas en la LO 8/2007 nos fuerza a preguntarnos por el grado de cumplimiento de los objetivos establecidos por el legislador en la Exposición de Motivos, a saber: a) La protección de la libertad de los partidos en el ejercicio de sus funciones, que justifica la prohibición de adoptar un modelo exclusivamente privado que impida, en la feliz expresión de Dworkin (2011, p. 55), «instituir una democracia de accionistas»; b) La preferencia por un modelo mixto compuesto por las aportaciones ciudadanas y la estatal calculada en función de la representatividad y garantes ambas de la independencia y suficiencia del sistema; c) La limitación y transparencia de las aportaciones privadas y la evitación del conflicto de intereses con la Administración Pública; d) El establecimiento de mecanismos de auditoría y fiscalización autónomos y suficientes.

La ley 8/2007 no cumple satisfactoriamente con los objetivos propios de un sistema de financiación auténticamente mixto. Privilegia descaradamente la captación de recursos públicos en atención a criterios legales que por su desproporcionada restricción del principio de igualdad de trato resultan dudosamente constitucionales. Partidos con expresividad social y dignos de atención estatal son excluidos del juego político. Los partidos mayoritarios y

${ }^{40}$ Cf. SÁnchez MuÑoz, O., «La financiación de los partidos políticos en España: ideas para un debate», op. cit., p.172.

${ }^{41}$ Cf. SÁnchez MuÑoz, O., «La financiación de los partidos políticos en España: ideas para un debate», op. cit., p.174. 
nacionalistas reciben una ayuda estatal que los coloca en franca ventaja competitiva con el resto de formaciones políticas. Una y otra circunstancia acaban por contribuir a la periclitación de nuestro sistema de partidos toda vez que la gobernabilidad no se encuentra en riesgo.

El efecto reflejo de este estado de cosas es la reducción de las fuentes de financiación privada a una posición secundaria. Los estímulos fiscales a las donaciones y cuotas son insuficientes para el logro el necesario reequilibrio que permita ir reduciendo paulatinamente la dependencia de las subvenciones estatales. Una situación que, como se analizará en el siguiente apartado, la reforma operada por la LO 5/2012 no ha reconducido en los términos deseables.

\section{LA LEY 8/2007 Y LA REFORMA DE 22 DE OCTUBRE DE 2012 (LO 5/2012): VIEJOS PROBLEMAS, SOLUCIONES PARCIALES}

Es lugar común afirmar que la Ley 8/2007 ha producido resultados desiguales en materia de financiación y que, en general, ha supuesto una ocasión perdida para acabar con uno de los males endémicos de la financiación partidista: la financiación irregular y la falta de transparencia. Los avances en la fiscalización de la financiación ordinaria y la prohibición de las donaciones anónimas merecen el debido reconocimiento. Por el contrario, cabe reprochar al legislador la inconcreción general de la ley y, especialmente, la inseguridad jurídica provocada por el oscurantismo legal alrededor de la condonación de deudas de los partidos. Una situación que, como se verá en el apartado siguiente, la reciente reforma operada por la LO 3/2015 ha reconducido al prohibir la condonación total o parcial de las deudas contraídas con las entidades de crédito.

El principal reproche que cabe hacer, con todo, a la LO 8/2007 ha sido la injustificada insistencia del legislador en seguir haciendo depender el sostenimiento de los partidos de las arcas del Estado. La justificación ofrecida para semejante actitud es tan «poderosa» como discutible. La financiación estatal, dicen sus máximos responsables, es la única fórmula eficaz para garantizar la independencia funcional y la estabilidad del sistema. Una verdad susceptible de ser matizada si nos ceñimos a los indicadores de opinión del CIS sobre la consideración de los partidos como uno de los principales problemas del país y la creciente desconfianza de la ciudadanía en el sistema político en general ${ }^{42}$. La historia política reciente invita igualmente a poner en entredicho dicha afirmación ya que la sobrefinanciación pública ha termi-

${ }^{42}$ Vid. Informe CIS Julio 2014 disponible en <http://www.cis.es/cis/opencm/ES/1_ encuestas/estudios/ver.jsp?estudio=14099>, (último acceso el 03/11/2014) 
nado por ser fuente de despilfarro y estímulo adicional al crecimiento descontrolado de los gastos de los partidos.

La actual coyuntura de crisis económica, junto a una intensa presión social en pro de medidas de reequilibrio y verdadero control, ha obligado a los partidos mayoritarios a activar el mecanismo de reforma de la LO 8/2007 mediante la LO 5/2012, de 22 de octubre. La labor reformista puede considerarse una vez más incompleta e irregular. Los avances habidos en los puntos clave del sistema de financiación -fuentes de financiación, mecanismos de fiscalización y transparencia y publicidad de las cuentas de los partidos- han sido nuevamente insuficientes.

La lectura de la Exposición de Motivos de la LO 5/2012 permite afirmar que los partidos continúan adoleciendo de auténtica voluntad para poner fin a la hiperdependencia de los presupuestos públicos. La reforma les garantiza la continuidad funcional con cargo a las finanzas estatales. La postura acertada hubiera sido la sustitución del modelo actual, dudosamente constitucional, por uno caracterizado por un mecanismo de participación fiscal y en todo caso de limitación del techo de gasto público. El mantenimiento del caudal público de subvenciones, a pesar del recorte anunciado, tiene el efecto reflejo de reforzar la posición de privilegio de los partidos frente a otras organizaciones sociales.

El legislador podría haberse hecho eco de algunas medidas dirigidas a equilibrar las fuentes de financiación vigentes en el derecho comparado. En este sentido, son destacables los notables esfuerzos realizados por el legislador alemán. El enfoque sobre la naturaleza de los fondos públicos en la legislación alemana habla de financiar parcialmente la «actividad general» de los partidos. Ello se traduce, en lo que aquí interesa destacar, en la imposición de dos límites legales a las subvenciones estatales: un límite relativo (relative Obergrenze) y un límite absoluto (absolute Obergrenze). El límite relativo se traduce en que la financiación pública de un partido no supere la cantidad obtenida por medio de la financiación privada -cuotas de afiliados y donaciones básicamente- ${ }^{43}$. El límite absoluto impide a los partidos sobrepasar la cifra total de 133 millones de euros. Ambos puntos se dirigen, de acuerdo a la naturaleza mixta del sistema de financiación, a incentivar la captación de recursos económicos procedentes de la esfera privada.

Una de las debilidades de la LO 8/2007 era la remisión a la LOREG para la fijación de las subvenciones por gastos electorales. Nada ha cambiado en la reforma actual. Se mantiene la línea argumental, de acuerdo con SÁNCHEZ MuÑoz, de ampliar las subvenciones a todos aquellos partidos que alcancen una mínima expresividad electoral no determinada imperativamente por la

${ }^{43}$ Cf. Fernández Vivas, Y., «El régimen de los partidos políticos en Alemania», Teoría y Realidad Constitucional n $\mathrm{n}^{\circ}$ 31, 2013, p. 498. 
consecución de uno o más escaños. El criterio de reparto era otro de los puntos conflictivos. Nos decantamos en este aspecto por el criterio del número de votos obtenidos. Las peculiaridades de nuestro sistema de partidos, con organizaciones de fuerte implantación territorial, hace razonable establecer un coeficiente de sufragios situado en un mínimo del $0,5 \%$ a nivel nacional o bien el mantenimiento del $3 \%$ para aquéllos que concurran a un número limitado de circunscripciones ${ }^{44}$.

La LO 5/2012 mejora la regulación de la LO 8/2007 en materia de incompatibilidades y transparencia de las donaciones efectuadas a los partidos (arts. $4^{\circ}$ y $5^{\circ}$ ). La regulación anterior limitaba la incompatibilidad de financiación a aquellas entidades privadas con intereses en la Administración. La nueva regulación la amplia a aquellas empresas pertenecientes al mismo grupo o bien mayoritariamente participadas por aquéllas o sus fundaciones (artículo $4^{\circ} \mathrm{c}$ ). Igualmente acertada resulta la adición de la letra d) que impide a los partidos recibir donaciones de entidades privadas que reciban fondos públicos. Una y otra medida penaliza el ejercicio de prácticas irregulares de canje de contribuciones a cambio de contratos o servicios públicos en manos de partidos gobernantes.

Uno de los puntos conflictivos en materia de financiación privada de la LO 8/2007 era la posible condonación de deudas entre entidades bancarias y partidos. Se trataba, sin duda, de un medio a través del cual se instituyó una vía legal, que no ética, de donaciones encubiertas y de intercambio de favores, muchos de ellos de dudosa legalidad, entre las entidades bancarias y las organizaciones partidarias ${ }^{45}$. El legislador tomó una actitud más decidida en este punto al establecer en el art. $4,4^{\circ}$ al limitar la condonación de deudas por entidades de crédito a los $100.000 €$ anuales.

Complementariamente, les impone la obligación de informar al Tribunal de Cuentas y al Banco de España. Esta limitación, aun acertada, puede dar lugar indirectamente a situaciones de financiación privilegiada que favorezca a aquellos partidos con mayor presencia institucional. Las instituciones financieras, que no se destacan por sus políticas distributivas precisamente, pueden mostrar mayor interés en condonar deudas a aquellos partidos financieramente más potentes frente a otros con recursos financieros menores.

Otra de las demandas clásicas en materia de financiación privada era la exigencia de limitar las donaciones privadas que los partidos pueden recibir. En una sociedad de marcado acento capitalista, donde el poder económico

${ }^{44}$ Cf. SÁnChEz MuÑoz, O., «La financiación de los partidos políticos en España: ideas para un debate», op. cit., p. 188.

${ }^{45}$ Cf. Coello de Portugal, J.M., «La Ley Orgánica 5/2012, de 22 de Octubre, una buena reforma en una buena dirección del régimen de financiación de los partidos políticos», Foro, Nueva Época, vol. 15, n 2, 2012, p. 340. 
ejerce una desmedida influencia sobre el poder político, la desregulación de posibles donaciones, y máxime las anónimas, podría traducirse en la búsqueda de tratos de favor de los partidos en el poder. Es, sin duda, uno de los factores de mayor riesgo en el logro de la igualdad de oportunidades que debe orientar el sistema de financiación.

La prohibición de donaciones anónimas, finalistas o revocables del artículo 5.1 de la LO 8/2007 ha supuesto un claro avance en la limitación de estas prácticas. Esta medida se ve complementada con otras que refuerzan la debida transparencia y publicidad exigible en materia financiera. La legalidad de las donaciones está condicionada a la creación de una cuenta bancaria específica en la cual ha de identificarse con precisión la procedencia de los fondos y el destino de los mismos [arts. $4^{\circ}$ e) y f) según nueva redacción dada en la LO 5/2012]. Otro acierto legislativo recogido en esta reforma decía a respecto de la obligación de notificar al TC en un plazo de máximo de 3 meses las donaciones que por su cuantía -superiores a $50.000 €$ - resultasen especialmente sensibles y las de bienes inmuebles en todo caso. El legislador, como se verá, ha adoptado una actitud aún más decidida en la LO 3/2015 al reducir el límite a los $25.000 €$.

La idoneidad de estas medidas, indudable avance en materia de transparencia y publicidad, debe relativizarse si se entiende que el verdadero problema no es tanto la identificación de las donaciones sino la opacidad de aquéllas que, conociéndose su existencia, escapan al control del Tribunal de Cuentas y al conocimiento directo de los electores y que continúan siendo una fuente de financiación irregular de los partidos. La realidad política de los últimos meses nos da la razón.

La publicidad y control de las actividades económicas de los partidos es otro de los elementos nucleares que permiten definir a un sistema de financiación como legítimo. El garantizar la rendición de cuentas y el acceso de la ciudadanía a la información veraz y actualizada de las cuentas de los partidos debe entenderse como una práctica que fortalece las instituciones democráticas y un dique de contención de posibles actitudes irregulares o directamente delictivas. La LO 8/2007 supone un discreto avance -no exento de lagunas- en la imposición de controles que permitan ejercer a los poderes públicos labores de fiscalización y rendición de cuentas suficientemente garantistas.

El art. 14 de dicha ley obliga a los partidos por primera vez a llevar una contabilidad detallada en base a criterios contables generalmente aceptados. Los dirigentes pasan a ser responsables de la veracidad de las cuentas anuales presentadas. Con ello se acaba con la indefinición de la Ley de 1987. Resulta igualmente acertada la reciente adición en la LO 5/2012 de un apartado (octavo) que obliga a los partidos a hacer públicos los datos de sus cuentas de resultados, balances y situación crediticia una vez auditados por el TC. La 
eficacia de esta última medida, más allá de las buenas intenciones del legislador, se resiente ante el retraso con que el propio TC emite sus informes anuales. Una situación parcialmente corregida por el esfuerzo del propio Tribunal que, a pesar de las tradicionales trabas con que los partidos cumplen la obligación de cooperación del artículo 19, ha logrado en el año de 2014 auditar las cuentas de los ejercicios 2009-2012 ${ }^{46}$.

Otra de las peticiones desatendidas por la LO 5/2012 -y corregida por la LO 3/2015- era la mejora de las redes de colaboración con otras entidades públicas como la Agencia Tributaria y el Banco de España ${ }^{47}$. Tampoco resulta de gran ayuda el que los esfuerzos por incrementar los medios materiales y humanos con que cuenta dicho Tribunal -que asciende a un presupuesto de 60 millones de euros y una plantilla de 700 empleados- hayan quedado recientemente en entredicho ante los frecuentes casos de nepotismo y enchufismo en la contratación y cobertura de vacantes, originándose en algunos casos auténticas sagas familiares ${ }^{48}$.

La contabilidad interna de los partidos es otro de los temas candentes que precisa de otra respuesta jurídica. Se ha apuntado como medida adicional de transparencia el sometimiento de las cuentas a una auditoría externa independiente de acreditada solvencia. Esta medida fue puesta en práctica con escaso éxito en el contexto del «caso Bárcenas». El Partido Popular convocó un concurso que terminó quedando desierto ante la negativa de las principales auditoras -Deloitte, PwC, KPMG- motivada por las múltiples trabas establecidas por la dirección del partido y que, a su juicio, dificultaban notablemente la obtención de un resultado acorde a las buenas prácticas en auditoria. No han faltado voces que apuntaban a la falta de estímulo de las grandes auditoras ante posibles represalias en forma de pérdida de contratos futuros ${ }^{49}$. Ya sea por las resistencias de los partidos, ya sea por la peligrosidad que las compañías auditoras perciben en auditar a los partidos, esta medida es de eficacia muy limitada.

${ }^{46}$ Datos disponibles en <http://www.tcu.es/tribunal-de-cuentas/es/search/alfresco/ index.html?fis $=$ true $>$ (último acceso el 14/05/2015)

${ }^{47}$ En comparecencia ante el Congreso durante 2013, el Presidente del Tribunal de Cuentas, Ramón Álvarez de Miranda reconocía que a pesar de las mejoras de la Ley $8 / 2007$, siguen siendo insuficientes las capacidades reales del Tribunal de Cuentas para recoger y cruzar las informaciones obtenidas con diversos organismos, en particular la Agencia Tributaria y la Seguridad Social. Disponible en $<$ http://politica.elpais.com/politica/2013/02/12/actualidad/1360673268_115120.html > (Acceso el 30/10/2014)

${ }^{48}$ Información disponible en $<$ http://politica.elpais.com/politica/2014/06/09/actuali$\mathrm{dad} / 1402333463$ 591562.html >, (último acceso el 28/10/2014)

${ }^{49}$ Información completa disponible en el diario económico Expansión en la dirección: <http://www.expansion.com/2013/02/18/economia/1361203588.html> (último acceso el 28/10/2014) 
El art. 16 merece especial atención. Este dispositivo, regulador de los medios de control externo, define las competencias del organismo encargado de la fiscalización de la actividad económica de los partidos, el TC. Nos encontramos ante el artículo de la Ley que más críticas ha recibido por parte de la doctrina, medios de comunicación y sociedad por cuanto su redacción pone en tela de juicio la capacidad de fiscalización e independencia real del Tribunal.

La naturaleza y capacidad de intervención y fiscalización del TC es otro de los clásicos puntos conflictivos del sistema de control de los partidos. Una queja que, a pesar de su coherencia y oportunidad, no recibe la deseada respuesta legislativa. El proceso de designación de los componentes del Tribunal está regulado en el artículo 30.1 de la LOTC. Los 12 magistrados del Tribunal son nombrados por mayoría de $3 / 5$ en cada una de las Cámaras, 6 en el Congreso y otros 6 en el Senado. El procedimiento es, en la práctica, prerrogativa final de los dos grandes partidos políticos, PP y PSOE. La práctica habitual de reparto de los cargos entre los grupos políticos dominantes, colocando mayoritariamente a antiguos diputados y senadores $u$ otros responsables que han desempeñado cargos políticos relevantes en los partidos a los que se supone deben controlar, no contribuye precisamente a reforzar la imagen de imparcialidad e independencia funcional que se le ha de suponer a este órgano. No sin cierta dosis de razón, a este órgano se le ha dado el nombre de «tigre de papel» $»^{50}$.

La tan ansiada recuperación de la credibilidad de esta institución fiscalizadora debe comenzar por seguir la orientación del Tribunal Supremo, quien ha denunciado recientemente la peligrosa deriva de politización del TC motivada por la desproporción existente entre funcionarios de libre designación -prerrogativa de los dos principales partidos- y funcionarios de carrera.

El apartado $3^{\circ}$ del art. 16 merece comentario aparte. El Tribunal de Cuentas dispone de 6 meses desde la recepción de la documentación exigida para emitir el informe de adecuación y conformidad o bien para denunciar las infracciones cometidas. El último informe emitido por el Tribunal es el correspondiente al ejercicio de 2012. Una grata noticia si consideramos que la norma común venía siendo la de retrasos por tiempo de 4 a 6 años. La elaboración del Plan de Contabilidad adaptado a los partidos en septiembre de 2013 que finalmente introduce un criterio unificado de análisis contable aportará un plus de seguridad jurídica que contribuirá a la mejora de la calidad y la agilidad de los procesos de fiscalización. Sería igualmente deseable que los partidos cumpliesen con la obligación impuesta por el artículo 19 de proveer en tiempo y forma la documentación financiera al TC. Por el mo-

50 Vid. García ViÑUELA, E., «Un tigre de papel». Disponible en $<$ http://elpais.com/ diario/2005/12/18/opinion/1134860409_850215.html>. (último acceso el 30/10/2014) 
mento, de poco parecen servir las continuas recomendaciones de mayor agilidad en los informes del $\mathrm{TC}^{51}$.

La mejora del régimen sancionador era otro de los asuntos pendientes de mejora en la LO 8/2007. La LO 5/ 2012 reforzó la capacidad sancionadora del Tribunal dando una mayor densidad y concreción normativa al conjunto de sus atribuciones (artículos 7 y 8). Otros avances positivos fueron el refuerzo de las capacidades sancionadoras del TC en materia de donaciones. El Tribunal dispone de legitimación para imponer severas multas económicas y retener subvenciones a aquellos partidos que contravengan las disposiciones legales sobre donaciones o bien obstruyan la labor del Tribunal reteniendo información útil para la auditoria de las cuentas.

La eficacia de estas medidas, con todo, se ve afectada por un conjunto de circunstancias reales no tenidas en cuenta por el legislador. El art. $7^{\circ}$ de la reforma optó por mantener el plazo de 4 años de prescripción de las infracciones contenidas en la ley. La prescripción, no cabe duda, es un instituto jurídico de innegable relevancia en el ordenamiento jurídico. La crítica se centra en el inicio de su cómputo temporal -el momento de la comisión de la infracción-y, sobre todo, en el mantenimiento del plazo de 4 años. Si lo que se pretendía era dotar de verdadera capacidad sancionadora al TC, no se entiende que el legislador no ampliase el límite temporal habida cuenta de los múltiples inconvenientes y trabas con que el Tribunal viene trabajando y que motivan los enormes retrasos en la emisión de los informes. Una situación que, como se verá en el siguiente apartado, el legislador ha resuelto parcialmente en la reciente reforma LO 3/2015.

El escenario de inseguridad jurídica del art. $7^{\circ}$ se complementa con la regulación del artículo $8^{\circ}$ de la LO 5/2012. La posible sanción impuesta por el Tribunal es lógicamente susceptible de ser recurrida en vía contenciosoadministrativa ante el Tribunal Supremo, produciéndose la suspensión automática de la ejecución de la sanción. Si nos atenemos a la media con que el TS viene resolviendo estos recursos -unos 17 meses-, el resultado es el refuerzo de una lentitud e incertidumbres jurídicas contrarias a la deseable celeridad procesal en materia sancionatoria.

Este enrevesado escenario -caracterizado por la natural opacidad de las donaciones anónimas, las artimañas contables con que los partidos fraccionan las donaciones y las trabas que el TC debe sortear para obtener la información contable de los partidos- y sumado a la lentitud con que el TS dicta sentencia definitiva acaba por perjudicar a los principios de celeridad y transparencia que deben guiar la fiscalización de la actividad de los partidos. Un

${ }^{51}$ En este sentido, resulta de especial utilidad la lectura de la Resolución de la Comisión Mixta de relaciones con el TC de 11 de marzo de 2014, disponible en <http://www. boe.es/diario_boe/txt.php?id=BOE-A-2014-5010 > . (Último acceso el 14/05/2015). 
enfoque más amplio de las prerrogativas del TC que le permitiría tomar la iniciativa en la investigación sin depender casi en exclusiva de la buena voluntad y diligencia de los partidos en la entrega de la documentación sería una medida acertada.

\section{UNA NUEVA REFORMA EN FAVOR DEL CONTROL DE LA ACTIVIDAD ECONÓMICO-FINANCIERA DE LOS PARTIDOS: LA LEY ORGÁNICA 3/2015, DE 30 DE MARZO}

La aparición de nuevos escándalos de financiación irregular de los partidos -posibilitados entre otros factores por la insuficiencia de los controles establecidos en la reforma de 2012- y la lógica corriente de indignación social catapultó la respuesta de las instituciones en busca de una normativa que reforzase la eficiencia de los mecanismos de control y transparencia. Los principales Grupos Parlamentarios, nos dice el Preámbulo de la LO 3/2015, suscribieron un compromiso en febrero de 2013 que ha terminado cristalizando en la reciente aprobación de una nueva Ley Orgánica, la 3/2015. Este dispositivo introduce nuevas reformas dirigidas a robustecer jurídicamente los principios de transparencia y control que deben presidir la actividad financiera de los partidos y a mejorar el régimen contenido en la anterior reforma legal.

El grueso de las reformas en materia de financiación están contenidas en el artículo $1^{\circ}$. Suponen una vuelta de tuerca en el fortalecimiento de los controles administrativos sobre las fuentes de financiación privada y están dirigidas principalmente a la imposición de límites a las donaciones realizadas por personas físicas, la total prohibición de donaciones realizadas por personas jurídicas y entes sin personalidad jurídica y la imposición de medidas adicionales de transparencia a los partidos políticos. Dicho en otros términos: el legislador ha dotado de mayores competencias a entidades públicas - principalmente, el TC y el Banco de España- y ha impuesto nuevas obligaciones en materia de transparencia y publicidad a los partidos en la confianza de que una normativa más prolija reduzca los casos de financiación irregular. Hubiera sido deseable, y con ello nos adelantamos a las conclusiones finales, que el legislador hubiera aprovechado esta nueva reforma para reforzar el régimen jurídico de las fuentes de financiación privadas y reducir la dependencia de los partidos de las arcas del Estado. Quizás en una nueva ocasión se haga eco de esta clásica reivindicación de buena parte de la doctrina y la sociedad y con ello difumine la sensación de inconstitucionalidad que paira sobre el modelo de financiación legalmente vigente.

El apartado Uno del artículo $1^{\circ}$ da nueva redacción a los apartados a) y b) del artículo $2^{\circ}$ de la LO 8/2007. El apartado a) se limita a eliminar los términos adherentes y simpatizantes. El apartado b) introduce una nueva fuente de 
financiación privada en la forma de aquellas actividades que se vengan desarrollando tradicionalmente en las sedes de los partidos y que promuevan el contacto e interacción con los ciudadanos. Tales actividades quedan sometidas a su reflejo contable y al control del Tribunal de Cuentas.

El apartado Dos del artículo $1^{\circ}$ concentra el grueso de las reformas al añadir al artículo $3^{\circ}$ de la LO 8/2007 cuatro nuevos epígrafes. El epígrafe Seis establece un mecanismo de control adicional -debe decirse, de dudosa utilidad- al exigir el acuerdo previo del Consejo de Ministros para aquellos supuestos en que el montante de la subvención exceda de los doce millones de euros. Un acuerdo que no conlleva, como nos dice la ley, la aprobación directa del gasto, que seguirá correspondiendo al órgano competente para la concesión de la subvención. No resulta fácil entender la finalidad buscada por el legislador al otorgar competencias en materia de financiación al Poder Ejecutivo. Si se quiere imponer un doble filtro, se podría haber seguido el modelo de Comisión Mixta utilizado en las relaciones con el TC compuestas por el conjunto de los Grupos Parlamentarios.

El epígrafe Siete del apartado Dos condiciona el pago de las subvenciones a la acreditación de hallarse al corriente en el cumplimiento de sus deberes tributarios y de Seguridad Social. Tampoco podrá el partido recibir subvenciones si se encuentra pendiente de reintegrar alguna subvención u otra ayuda anterior. El epígrafe Ocho impide el cobro de subvenciones a aquellos partidos que no presenten en tiempo y forma las cuentas conforme a lo establecido en el artículo 14. Por último, el epígrafe Nueve obliga a las Administraciones Públicas a detallar al menos una vez al año las subvenciones dadas a los partidos así como sus perceptores, de conformidad con la Ley 19/2013, de 9 de diciembre, de transparencia, acceso a la información y buen gobierno.

El apartado Tres del artículo $1^{\circ}$ completa la redacción original del artículo $4^{\circ}$ de la Ley $8 / 2007$ referido a las donaciones privadas a los partidos. Introduce, concretamente, dos medidas de transparencia largamente demandadas: a) La imposibilidad de realizar donaciones a los partidos procedentes de personas físicas que sean parte de un contrato vigente de los previstos en la legislación de contratos del sector público; b) La obligatoriedad de que los partidos consignen las donaciones recibidas en cuentas abiertas exclusivamente a este fin y que informen a las entidades de crédito y al TC de la existencia de las mismas. A su vez, las entidades de crédito informarán anualmente a este último de las cantidades recibidas por este concepto. Por último, las letras c) d) e) y f) introducen medidas dirigidas a la mejora de la transparencia y publicidad en la recepción y gestión de donaciones procedentes de personas físicas.

El apartado Tres in fine del artículo $1^{\circ}$ establece la imposibilidad de que los partidos políticos se beneficien de tipos de interés inferiores a las condi- 
ciones de mercado en la negociación de las deudas contraídas con entidades de crédito. Igualmente se establece un elemento de transparencia adicional al exigirle a aquéllos que informen al Banco de España y al Tribunal de Cuentas. Se prohíbe, por último, la condonación de deudas -total o parcialmentea los partidos por parte de las entidades de crédito. Todas estas medidas, en principio acertadas, pretenden ser diques de contención para refrenar las pulsiones de continuo endeudamiento de los partidos así como limitar situaciones de indeseada dependencia de los partidos frente a las entidades de crédito que estimulen actitudes clientelares.

El apartado Cuatro del artículo $1^{\circ}$ introduce reformas estimables en el artículo $5^{\circ}$ de la LO 8/2007. La primera es la reducción de las aportaciones de personas físicas del límite anterior de $100.000 €$ anuales a la cantidad de $50.000 €$. Hubiera sido deseable que este límite se hubiera mantenido igualmente en el caso de las donaciones en especie por personas físicas. Mayor calado tiene, sin duda, el epígrafe c) que establece la prohibición total de donaciones provenientes de personas jurídicas y de entes sin personalidad jurídica. Esta era una medida largamente demandada en pro del principio de igualdad de oportunidades. Por último, el legislador ha rebajado a la cantidad de $25.000 €$ el límite de aquellas donaciones que han de ser comunicadas al TC.

El apartado Seis del artículo $1^{\circ}$ incide en la publicidad y transparencia de las cuotas de los afiliados mediante la apertura de cuentas bancarias destinadas exclusivamente a este fin. El legislador ha dejado pasar nuevamente la oportunidad de elevar el límite de $600 €$ en la deducción del IRPF de las cuotas de afiliados establecido en el artículo 12 de la LO 8/2007. Esta medida funcionaría como un estímulo adicional para incrementar la exigua financiación privada de los partidos españoles.

El otro gran bloque de reformas legales se centra en las obligaciones contables y financieras del artículo 14 de la LO 8/2007. La lectura del apartado Tres rebela el esfuerzo del legislador por concretar el contenido de la Memoria Anual. Las reformas de mayor calado se centran en reforzar la transparencia y publicidad de las cuentas de los partidos con dos medidas complementarias: a) obligándoles a que en el plazo de un mes desde la fecha de envío de la documentación al TC publiquen las cuentas detalladas en su página web; b) a que publiquen el informe del TC en el plazo máximo de 15 días desde su recepción.

El artículo 14 bis introduce una novedad sin precedentes: la designación de un responsable de la gestión económico-financiera del partido cuyo nombramiento se halla condicionado al cumplimiento de unas condiciones tasadas de idoneidad y a un régimen de incompatibilidad que pretenden garantizar su buen hacer.

La fiscalización y control de las cuentas de los partidos es el gran caballo de batalla de la financiación y fuente de las mayores críticas doctrinales. El 
legislador ha reforzado las competencias del $\mathrm{TC}$ al permitir examinar las cuentas de aquellos partidos que no reciban subvenciones públicas. El apartado tres introduce una nueva obligación para los partidos, cual es la de presentar sus cuentas de acuerdo a los principios de gestión económica que les sean exigibles en función de la naturaleza de sus operaciones. En el propio artículo 16 se establece un apartado bis por el que se habilita a la Comisión Mixta para las relaciones con el TC a solicitar la comparecencia del responsable económico de los partidos al efecto de informar de las infracciones o prácticas irregulares detectadas por este último.

El artículo 17, relativo a las infracciones, ha sido objeto de concreción jurídica en unos términos globalmente acertados. Se amplía el catálogo de conductas tipificadas como sancionables y se incrementan las sanciones económicas a los partidos. La reforma legal diferencia entre infracciones muy graves, graves y leves y otorga plazos de prescripción diferentes según se trate de una u otra infracción. En este punto el legislador ha optado por incrementar en un año la prescripción de las infracciones muy graves (5 años) y reducir en un año las conductas calificables como graves (3 años). Las infracciones leves prescribirán a los dos años. El inicio del cómputo temporal sigue siendo, equivocadamente, el del inicio de la infracción.

Una valoración diferente merece el tratamiento que el legislador ha dado a la infracción de no presentar en tiempo y forma las cuentas correspondientes al ejercicio natural. La LO 8/2007 la consideraba infracción muy grave y le otorgaba un plazo de prescripción de 4 años. La LO 3/2015 la califica como infracción grave y reduce el plazo de prescripción a 3 años. Un plazo incierto si se atiende al retraso histórico con que el TC viene auditando las cuentas de los partidos -en la actualidad los informes de fiscalización más recientes corresponden al año $2012^{52}$. Dicho en otros términos: el hacer depender la ampliación de los plazos de prescripción de la repetición de una infracción que la reforma de 2012 ya calificaba como muy grave y para la cual establecía un plazo de prescripción de cuatro años va en la dirección contraria a la adopción de un marco normativo que otorgue mayor seguridad jurídica y que tenga en cuenta los factores que vienen dilatando en el tiempo la función de fiscalización del TC.

Otro bloque de análisis y objeto de críticas en el apartado anterior es el correspondiente a las fundaciones y se halla contenido en la Disposición Adicional Séptima de la LO 3/2015. El legislador ha optado por mantener en bloque las determinaciones legales. Por ello, nos remitimos a las consideraciones realizadas en el apartado anterior.

${ }^{52}$ Datos disponibles en <http://www.tcu.es/tribunal-de-cuentas/es/search/alfresco/ index.html?entrance=FIS $>$, (último acceso el 12/05/2015). 
Cierra este análisis la reforma de la LO 2/1982, de 12 de mayo, del Tribunal de Cuentas contenida en el Artículo $3^{\circ}$ de la LO 3/2015. Cabe valorar positivamente la atribución de competencias reglamentarias sobre su funcionamiento y organización y sobre el estatuto de personal y servicios. Estas medidas posibilitan que el TC disponga de una mayor autonomía funcional que debería redundar en la mejora de sus funciones fiscalizadoras. El apartado Cuatro del citado artículo $3^{\circ}$ obliga al Estado y demás entidades integrantes del sector público a facilitarle la información y con ello contribuir al adecuado cumplimiento de sus funciones. Igualmente, le otorga al TC la capacidad de celebrar convenios de colaboración al objeto de agilizar los trámites en el intercambio de informaciones. El apartado Cinco, por su parte, reitera la obligación de cooperación para las entidades de crédito en el control y fiscalización de las cuentas de los partidos. Se mantiene, con buen criterio, el anonimato de los donantes con la salvedad de aportaciones que superen los $3.000 €$ en el curso de un año natural.

El refuerzo de las competencias organizativas del TC debe ser recibido con moderado optimismo. El elemento central del que depende la independencia real del Tribunal -el procedimiento de selección de los miembros establecida en el artículo 30.1- no ha sido objeto de reforma alguna. El enroque del legislador en mantener un procedimiento que genera encendidas y razonadas críticas respecto a su independencia resta empaque a los avances legislativos contenidos en la LO 3/2015. Reiteramos la conveniencia de adoptar un modelo que prime el equilibrio entre los miembros designados por las Cortes Generales y los funcionarios de carrera independientes. De esta forma, la independencia funcional de los Consejeros de Cuentas del artículo 30.2 dejará de estar bajo sospecha.

\section{CONCLUSIONES}

La financiación política es materia tan relevante como problemática al afectar directamente a determinados principios fundamentales del Estado democrático con innegable repercusión en la legitimidad global del sistema político. La solución legislativa que goza de mayor respaldo doctrinal es la configuración de un modelo mixto. La financiación pública, en el ojo del huracán por su incontinencia presupuestaria, se justifica en la garantía del correcto desempeño de las funciones constitucionales que le son reconocidas a los partidos en el artículo $6 \mathrm{CE}$ y otras que, no teniendo expreso reconocimiento constitucional, resultan igualmente dignas de atención estatal. La financiación privada se fundamenta en la libertad de acción de los partidos y su necesaria independencia respecto del Estado. El correcto equilibrio entre una y otra fuente facilitaría el cumplimiento de los valores constitucionales en juego. 
Desde la entrada en vigor de la primera ley de financiación de Partidos (en 1978) hasta la vigente Ley $8 / 2007$, el legislador español ha ido intensificando exponencialmente la participación estatal en el sostenimiento de los partidos. Los valores mínimos de $75 \%$ de financiación pública hablan por sí solos del desequilibrio existente entre las diferentes fuentes de financiación. Una desproporción que acaba por desnaturalizar el carácter mixto del modelo de financiación vigente. Efecto colateral de esta realidad es la hiperdependencia que los partidos han desarrollado y parecen querer conservar respecto de los fondos procedentes del Estado.

La ingente cantidad de recursos estatales no ha servido ni para lograr la estabilidad funcional de los partidos ni como dique de contención de los numerosos escándalos de financiación irregular que vienen protagonizando la vida política de los últimos meses. Estas prácticas se han visto favorecidas por la laxitud y vaguedad de la normativa vigente en materia de donaciones y relaciones de los partidos con las entidades crediticias. La LO 3/2015 supone un innegable avance al prohibir las donaciones de personas jurídicas y entes sin personalidad jurídica, reducir las de personas físicas a la cantidad de $50.000 €$ anuales y prohibir recibir a los partidos donaciones procedentes de personas físicas inmersas en procesos de contratación públicos.

Una de las consecuencias más criticables del actual sistema de financiación es la persistencia de reglas contrarias a la igualdad de trato que debe regir la competición entre los partidos. Se trata de normas de dudosa constitucionalidad cuyo efecto directo es el refuerzo del desorbitado control del sistema político que ya de por sí ejercen los partidos dominantes. La prohibición de las donaciones por personas jurídicas debe ser considerada una medida positiva en pro de la igualdad de oportunidades ante la tendencia «natural» que las empresas privadas tienen de primar a los partidos gobernantes.

La LO 8/2007 viene mostrándose ineficaz a la hora de promover uno de los objetivos de la mejora del régimen fiscal introducido en la ley: el equilibrio entre fuentes financieras propio del sistema mixto. La regulación contenida no favorece las microdonaciones provenientes de un elevado número de ciudadanos por las razones explicadas anteriormente. En este sentido sería oportuno considerar la revisión a la baja de los límites establecidos en la ley y la implementación de algún mecanismo de desgravación fiscal regresivo. El otro pilar, las cuotas de los afiliados, merece una revisión legislativa orientada a incrementar la cantidad susceptible de deducciones fiscales. La LO 3/2015 continúa dócilmente la senda de su antecesora.

Si valoramos conjuntamente la respuesta que la LO 8/2007 y las LO $5 / 2012$ y 3/2015 han dado a los ejes cardinales de la financiación de los partidos -el equilibro de las fuentes de financiación, la transparencia y publicidad de la contabilidad partidaria y la fiscalización eficiente de la actividad económico-financiera-, el resultado global continua siendo insatisfactorio. 
El principal reproche a la LO 8/2007 es la inexistencia de techo de gasto público en la financiación de los partidos. El legislador, eso sí, no se olvidó de establecer un límite de mínimos -el IPC- al montante de la financiación estatal. No parece prudente esperar la autolimitación financiera de los partidos al índice de precios de consumo. En este sentido, sería de esperar una reforma legislativa que al estilo del derecho comparado alemán y francés impusiera límites a la financiación pública estimulando a los partidos a tener un mayor activismo en materia de captación de recursos privados.

En materia de transparencia se han producido avances parciales. La obligación impuesta a los partidos de publicar en el plazo de 15 días sus cuentas una vez auditadas por el TC es, sin duda, un paso adelante. Sin embargo, esta medida pierde parte de su eficacia ante los retrasos con que el TC viene emitiendo sus informes -el último ejercicio auditado corresponde al año 2012-. El resultado obtenido es parcialmente contrario al esperado con la publicidad de las cuentas ya que al elector se le continúa hurtando la posibilidad de disponer de la información financiera de los partidos en un margen de tiempo aceptable.

El control de la actividad económico-financiera de los partidos, otro de los objetivos centrales de la LO 8/2007, es nuevamente un campo pendiente de mayor concreción jurídica. La reforma de la LO 5/2012 palió parcialmente esta situación. El legislador otorgó al Tribunal nuevas competencias sancionadoras permitiendo la retención de las subvenciones a aquellos partidos que no entreguen en tiempo y forma la documentación contable exigida por ley. La reforma de la LO 3/2015 ha mejorado la seguridad jurídica al eliminar la expresión sin causa justificada del artículo $7^{\circ}$ de la anterior reforma legislativa. Con ello se evita, como hasta el momento venía denunciando el TC, que los partidos se amparen en subterfugios obstruccionistas en la entrega de la documentación contable. Otro avance estimable de la última reforma legal es el incremento de las obligaciones de los partidos en materia de publicidad y transparencia y la concesión de mayores competencias organizativas y funcionales al TC tanto a nivel interno cuanto en las relaciones con la Administración del Estado y las entidades de crédito.

Cierra este apartado de conclusiones una cuestión que aunque es objeto de regulación en ley específica afecta directamente a la credibilidad del sistema de financiación de los partidos. Nos referimos al procedimiento de selección -o mejor dicho, reparto entre los dos grandes partidos- de los Consejeros del TC. Sería deseable que los partidos dominantes en el Congreso y Senado, el PP y el PSOE a la postre, siguiesen la recomendación del Tribunal Supremo de diciembre de 2012 de establecer una mayor proporción entre funcionarios de carrera y aquellos profesionales con evidentes lazos políticos. Este cambio de actitud contribuiría a mejorar no solo la imagen institucional del TC; también, y más importante si cabe, reforzaría la independencia 
funcional de sus miembros. La reciente reforma de la LO 3/2015 ha vuelto a ignorar esta clásica demanda que continuará colocando en jaque la independencia real del Tribunal de Cuentas.

A modo de reflexión final debe insistirse en que el modelo de financiación vigente necesita ser repensado en sus líneas maestras. Nos referimos, principalmente, al equilibrio de las fuentes de financiación. No deben olvidarse otras reformas puntuales que aun formando parte de otros cuerpos legales inciden en el sistema de financiación. Los continuos escándalos que vienen minando la credibilidad social en los partidos y aumentando el descrédito ciudadano en las instituciones democráticas merecen la continua vigilancia y una actitud decididamente reformista por parte de sus principales protagonistas. Ortega y Gasset decía que «la verdad ignorada prepara su venganza». Esperemos que el legislador no siga ignorando las deficiencias de nuestro sistema y continúe la senda reformista en favor de los principios cardinales de la financiación de los partidos: la igualdad de oportunidades, la transparencia y la publicidad.

TITLE: Revisiting the funding scheme of Spanish Political Parties. The Organic Law 8/2007 and the October 2012 and March 2015 reform.

RESUMEN: El presente artículo aborda un tema elemental para el correcto funcionamiento de los partidos políticos: el financiamiento de su actividad. Tras 35 años de gobierno democrático y varias leyes de financiación, no termina de obtenerse un marco jurídico suficientemente satisfactorio. Esta deficiencia justifica una reflexión crítica que persiga los siguientes objetivos: entender la relación simbiótica existente entre financiación de partidos y la estabilidad funcional del sistema representativo; analizar la conformación legal del modelo español de financiación, con especial énfasis en la vigente LO 8/2007; identificar los viejos males persistentes tras la reciente reforma legal -LO 5/2012, de 22 de octubre-y las soluciones establecidas por el legislador en la reciente LO 3/2015 que han pretendido paliar, que pretenden paliar, veremos con que fortuna, la insuficiencia legal en materia de financiación partidaria.

PALABRAS CLAVE: financiación partidos, democracia, transparencia, corrupción.

ABSTRACT: This article elaborates over a fundamental subject for the right functioning of political parties: the funding of its activities. After 35 years of democratic government with various laws passed on the financing activities of political parties, it has not been possible to obtain a satisfactory legal answer yet. This deficiency justifies the pursuance of a critical analysis which follows the following objectives: to contextualize and to understand the relevance of funding within political parties for the functional stability of the representative system; to analyze the Spanish financing 
model in democratic times, putting special emphasis on the current LO 8/2007 act; to reveal the persistence of old diseases after the recent legal reform - LO 5/2012, 22th of October-as well as the legal solutions established in the last reform by the LO 3/2015 passed with the aim of overcoming the legal lacks in the topic of political parties financing.

KEY WORDS: financing, parties, democracy, transparency, corruption.

RECIBIDO: 07.05.2015

ACEPTADO: 22.05.2015 